\title{
http://revistainvestigacionacademicasinfrontera.com
}

\section{LA CRIMINOLOGÍA COMO CIENCIA INTERDISCIPLINARIA Y SU RELACIÓN CON EL DERECHO PENAL.}

\author{
Lic. Armando Medina Wahnnatah ${ }^{1}$; Dra. María Guadalupe Almada Quintero ${ }^{2}$; Dr. Cirilo \\ Duarte Félix ${ }^{3}$; Verónica Avalos Wahnnatah
}

\begin{abstract}
Resumen
La criminología como ciencia busca coadyuvar en la reducción de las conductas delictivas con el estudio e identificación de las causas de su origen, su aplicación en el campo de la justicia penal va en aumento, se ha convertido en una ciencia independiente y autónoma, de gran relación con la ciencia penal. Este análisis va enfocado al estudio del hombre y su comportamiento con relación al fenómeno delictivo, con la transgresión a la ley partiendo de la premisa de que todos los seres humanos nacen libres y con derechos.

Como parte importante del estudio de la criminología y su relación con el derecho penal, resulta interesante analizar la conducta de las personas, y los factores o elementos que los llevan a cometer delitos. Es fundamental incluir en este análisis reflexiones acerca de la importancia del estudio de la pena como consecuencia jurídica y enfocar el análisis y reflexión a la mejor inserción del individuo autor del hecho ilícito en la sociedad.
\end{abstract}

Palabras clave: Criminología, victimología, pena, derecho penal

\footnotetext{
${ }^{1}$ Licenciado en Derecho por la Universidad de Sonora. Docente en la Universidad Estatal de Sonora. Campus Navojoa. licarmandomedinaw@hotmail.com

${ }^{2}$ Doctora en Planeación y Liderazgo Educativo por la Universidad del Valle de México. Campus Hermosillo. Docente en la Universidad Estatal de Sonora. magaq@hotmail.com

${ }^{3}$ Doctor en Investigación Educativa en la Instituto del Desierto de Santa Ana. Campus Navojoa. Docente en la Universidad Estatal de Sonora. duarte606@hotmail.com
} 


\title{
http://revistainvestigacionacademicasinfrontera.com
}

\begin{abstract}
Criminology as a science aims to contribute in the reduction of criminal behavior with the study and identification of the causes of its origin, its application in the field of criminal justice is on the rise, it has become an independent and autonomous science of great relationship with the criminal law science. This analysis will focus on the study of man and their behavior in relation to the criminal phenomenon, with the transgression of the law based on the premise that all human beings are born free and with rights.

As an important part of the study of criminology and its relationship with the criminal law, it is interesting to analyze the behavior of the people, and the factors or elements that lead them to commit crimes. It is essential to include in this analysis reflections about the importance of the study of the death penalty as a result legal and focus the analysis and reflection to the better integration of the individual author of the wrongful act in society.
\end{abstract}

Keywords: Criminology, victimology, penalty, criminal law

\section{Introducción}

Por su naturaleza, la criminología es una ciencia causal-explicativa, empírica e interdisciplinaria, intervienen en ella a la vez distintas ciencias entre las que destacan la antropología, la psicología y la sociología, esta convergencia de disciplinas es obligada y guarda estrecha relación con el derecho penal puesto que la comisión del delito es un comportamiento social, pero visto como un acto individual que comprende lo corpóreo y lo psíquico.

La criminología es una ciencia del "ser" en lo cual radica el aspecto empírico, por otra parte se encuentra el "deber ser" que corresponde a la parte del derecho, de la normativa. Desde este razonamiento, se parte de que la criminología es una ciencia empírica, que se inserta en lo real ya que su objeto de estudio; el delito, el delincuente, la víctima y el control social, son abordados por esta desde lo verificable, lo mesurable, su naturaleza empírica se apoya en los hechos, más que en las opiniones y la observación. Valora, ordena y orienta, conoce la 


\section{http://revistainvestigacionacademicasinfrontera.com}

realidad para explicarla, por otra parte, el principio interdisciplinario se debe a que son muchas las disciplinas científicas que se ocupan de estudiar al crimen como un fenómeno individual, pero con gran impacto social, todas estas con sus respectivos métodos, enfoques y de gran valor especializado que se complementan y propicia un sistema de retroalimentación.

Es importante retomar en este trabajo la relación de la criminología con el derecho penal, evidentemente, ambas encuentran como punto de coincidencia el delito, su estrecha colaboración cobra mayor importancia cuando las investigaciones criminológicas aportan elementos de gran valor para la construcción de normas jurídico penal.

\section{Método}

Para esta investigación se emplea un enfoque con elementos cualitativos, análisis de contenido y la interpretación de la información, con un diseño exploratorio para la obtención de información relacionada con una problemática o con el fenómeno a investigar (Hernández, Sampieri 2016). Son parte de este análisis aspectos teóricos y estudios doctrinarios que apoyan el estado del arte, al documentar aspectos generales de la criminología desde el punto de vista de su interdisciplinariedad y su estrecha relación y colaboración con el derecho penal. Lo anterior contribuye a la mejor comprensión de las normas jurídicas reguladoras del poder punitivo del estado, partiendo del delito, el delincuente y la víctima, la pena y consecuencias jurídicas.

\section{Resultados}

El comportamiento humano ha sido en todos los tiempos motivo de interés y preocupación por especialistas de diferentes disciplinas. La ciencia normativa se encarga del estudio del comportamiento regulado en las normas, los modelos de comportamiento humano que la ley 


\section{http://revistainvestigacionacademicasinfrontera.com}

describe como delitos y todas las sanciones que se podrían aplicar para cada comportamiento establecido.

La ciencia aplicativa, por su parte, se ocuparía en indagar las circunstancias instrumentales y personales en las que se realizó el hecho punible. De tal forma que el derecho penal es una ciencia normativa, la criminalística es una ciencia aplicativa y la criminología es una ciencia causal - explicativa.

Lo anterior, en relación con el tema de la criminología motivo de este análisis, según señala Flores (2008) parte desde sus primeras concepciones, término que fue usado inicialmente a mediados del siglo XVIII por el médico y antropólogo francés Paul Topinard, pero fue Raffaele Garofalo, jurista italiano, quien le dio notoriedad al poner el nombre de criminología a su obra publicada en Turín en 1885, obra que se hizo famosa y lo consagró junto a Cesare Lombroso y a Enrico Ferri, como fundador de la ciencia criminológica.

Este mismo autor retoma algunas conceptualizaciones destacando con relación a la criminología:

- "Ciencia que estudia el fenómeno delictual y ciertas áreas de la desviación social etiológicamente y con proyección profiláctica"

- "Disciplina que se ocupa del fenómeno sociopolítico criminalidad, a fin de reducir ésta a proporciones compatibles con el desarrollo sociopolítico nacional e internacional, según exigencias adecuadas de libertad, dignidad, igualdad y seguridad colectivas"

De igual forma, y citando a López (2017) se refiere a la criminología como "la ciencia empírica e interdisciplinaria que tiene por objeto el crimen, el delincuente, la víctima y el control social del comportamiento delictivo; y que aporta información válida, contrastada y fiable sobre la génesis, dinámica y variables del crimen problema social, así como sobre su prevención eficaz, las formas y estrategias de reacción al mismo y las técnicas de intervención positiva en el infractor". 


\section{http://revistainvestigacionacademicasinfrontera.com}

Continuando con este autor, aborda el estudio de la criminología en el siguiente sentido:

Desde el punto de vista del método, mencionando que es una ciencia empírica e interdisciplinar. Desde el punto de vista del objeto se conforma con cuatro elementos: el delito, el delincuente, la víctima y el control social del comportamiento delictivo.

Finalmente, afirma que la criminología tiene tres funciones:

a). - Proporcionar o suministrar una información valida y contrastada sobre la génesis, dinámica y las variables que inciden en el delito, tanto desde la perspectiva del delito como acto individual o aislado, como hecho social o fenómeno de masas.

b). - Desarrollar programas de prevención eficaz de lucha contra el crimen. Se le denomina finalidad preventiva.

c). - Crear técnicas de intervención positiva en la persona del delincuente. Son técnicas orientadas a la reinserción social del delincuente.

Por otra parte, en cuanto a la relación de la criminología con otras ciencias, muchas disciplinas se ocupan desde diferentes enfoques y perspectivas del estudio del delito, el delincuente, la víctima y el control social, con un objeto común del estudio del hecho criminal.

Es importante señalar, que la delimitación de la materia criminológica y de las disciplinas que versan sobre la misma es complicada, en la medida en que progresaba el conocimiento empírico sobre el crimen fueron surgiendo otras disciplinas destacando la Antropología Criminal, la Psicología Criminal, la Biología Criminal, la Sociología Criminal o la Victimología, etc.

La ciencia criminológica es interdisciplinaria y es importante resaltar que ninguna de las disciplinas que la integran puede ser excluyente de las demás. Cada campo del saber científico tiene un área de investigación propia, pero también sus limitaciones y condicionamientos, y por tanto su dependencia con las demás, a fin de tener una información totalizadora, global, multidimensional del problema del crimen, del delincuente, de la víctima 


\section{http://revistainvestigacionacademicasinfrontera.com}

y del control social, pertenecen a la criminología todas las disciplinas que se ocupan del estudio de la realidad criminal, en sus diversas fases (Hikal. 2009).

En este mismo sentido, Mendoza (2008) menciona que el principio interdisciplinario se halla significativamente asociado al proceso histórico de consolidación de la criminología como ciencia autónoma. Son muchas las disciplinas científicas que se ocupan del crimen como fenómeno individual y social, todas ellas con sus respectivos métodos, enfoques y pretensiones han ido acumulando valiosos saberes especializados sobre aquél.

El análisis científico reclama una instancia superior que integre y coordine las informaciones sectoriales procedentes de las diversas disciplinas interesadas por el fenómeno delictivo; que elimine posibles contradicciones internas e instrumentales un genuino sistema de retroalimentación, según el cual cada conclusión particular se corrige y enriquece al contrastarse con las obtenidas en otros ámbitos y disciplinas.

Por otra parte, continuando con este análisis y citando a Hassemer. \& Muñoz. (1989) en relación a la criminología con el derecho penal, este último puede ser definido como la rama del derecho positivo que fija los bienes jurídicos que han de ser protegidos penalmente y sobre esos principios variables en tiempo y espacio, configura específicamente los delitos y las penas que a cada uno de ellos le corresponde. Es aquella parte del orden jurídico que determina las conductas socialmente inaceptables y las sanciones aplicables. En un concepto formal, es producto del legislador en un momento dado y en un territorio. La criminología y el derecho Penal son dos ciencias distintas: el derecho penal es una ciencia "jurídica", "cultural", "normativa", del "deber ser". Por su parte, la criminología es una ciencia “empírica", una ciencia del "ser".

La ciencia penal en sentido amplio, se ocupa de la delimitación, interpretación y análisis teórico-sistemático del delito (concepto formal), así como de los presupuestos de su persecución y sus consecuencias. El objeto de la ciencia penal viene dado por las normas 


\section{http://revistainvestigacionacademicasinfrontera.com}

legales y quienes cultivan la misma emplean un método “deductivo-sistemático" para analizar el hecho criminal.

La criminología, por el contrario, se enfrenta al delito como fenómeno "real" y se sirve de métodos empíricos para examinarlo. Los criterios jurídico-penales no permiten una delimitación exhaustiva del objeto de la Criminología, por la misma razón que aquéllos no agotan, tampoco, el significado total del crimen como hecho real.

Nájera (2004) explica que el fin de la criminología consiste en penetrar en el Derecho Penal, hacerle evolucionar, supone una cierta compenetración de las dos disciplinas, la criminología debe dominar la elaboración de la técnica jurídica. Ello sugiere que el estudio criminológico debe estar teñido de esa relación indisoluble entre hecho y derecho. Hoy día asistimos a la concepción de un sistema penal que debe ser entendido como un objeto de conocimiento sociológico criminal, cuando se le plantea como mecanismo de control social. Intenta realizar el estudio criminológico entendiendo a la sociedad como el medio en donde vive y se desarrolla el individuo, en un clima de constante interacción con los demás. De ahí que el control social, entendido positivamente como "el conjunto de recursos de que dispone una sociedad para asegurarse de que los comportamientos de sus miembros se apegarán a las reglas y principios fijados", esto con el objetivo de que la sociedad se desarrolle en plenitud, y en un ambiente de tranquilidad y seguridad. De ahí que la prevención del fenómeno delictivo se torne en imperativa, pero siempre bajo un contexto garantista. Así, la prevención del delito para ser creíble debe ser eficaz, y por tanto debe estar sujeta a un continuo análisis criminológico, pues ello permitirá superar sus limitaciones y obstáculos prácticos.

Es entonces que el derecho penal y la criminología se tocan en un nivel empírico, que posibilita la aplicación de una adecuada política criminal. Pero además, ello permite que en un nivel epistemológico se involucre la formulación de orientaciones y principios normativos que mediante su aplicación práctica resultan eficaces para la prevención de estos fenómenos; gracias a la unión de esa aplicación complementaria, recíproca y conjunta de tales disciplinas. 


\section{http://revistainvestigacionacademicasinfrontera.com}

\section{Conclusiones}

Indudablemente la relación entre la criminología y el derecho penal es evidente, ambas ciencias se necesitan mutuamente, forman un complemento, mientras la criminología se muestra abierta a los cambios, adaptándose a los mismos, el derecho penal tiene una evidente vocación de permanencia, que se justifica en el principio de seguridad jurídica, que permite al ciudadano conocer las leyes, y por lo tanto los delitos y las penas.

Además, el derecho penal se instituye como ciencia normativa, del "deber ser", la criminología por lo tanto como ciencia del "ser". La delimitación se identifica por el método utilizado por cada una de ellas, mientras la primera utiliza el deductivo la segunda el inductivo.

El derecho penal se encarga de regular la conducta humana que se externa, que se materializa, para resguardar bienes jurídicos que equilibran la convivencia social, logrando garantizar la protección de los particulares.

Mientras que la criminología puede y debe desempeñar un papel importante al momento de determinar que hechos han de ser descriminalizados, de tal manera que la criminología debe de reducir o extender su propio objeto de regulación y que medios debe emplear para prevenir los hechos delictivos a la sociedad.

Así mismo, la criminología es una ciencia empírica, que se adapta a la realidad tal y como es, mientras que el derecho penal es más rígido, debido a la aplicación de los principios de certeza y seguridad jurídica. Uno de los principales aporte de la criminología es la explicación de la criminalidad, del comportamiento de los criminales como un problema de todos, de la propia sociedad y sobre todo, se encarga de la prevención del delito, de la reinserción del delincuente en la sociedad. 


\section{http://revistainvestigacionacademicasinfrontera.com}

\section{Referencias}

Flores C., C. (2008). Lecciones de Criminología. Caracas-Venezuela: Vadell Hermanos Editores. https://temasdederecho.wordpress.com/2012/06/04/la-criminologia-comociencia/

Hikal. W. (2009). Introducción al estudio de la criminología. http://sistemaucem.edu.mx/bibliotecavirtual/oferta/licenciaturas/criminologia/CRIMI 105/introduccion_al_estudio_de_la_criminologia.\%20listo.pdf

Hassemer. W. \& Muñoz. F. (1989). Introducción a la criminología y al derecho penal. http://nparangaricutiro.gob.mx/Libros/55.$\% 20$ Introduccion\%20A\%20La\%20Criminologia\%20Y\%20A1\%20Derecho\%20Penal $\% 20-\% 20$ Has.pdf

Hernández. S. (2016). Metodología de la investigación. 5ta. Ed. McGRAW-HILL / Interamericana Editores, S.A. DE C.V.

López Ll. J. (2017. La criminología como ciencia empírica e interdisciplinar. http://www.estudiocriminal.eu/wp-content/uploads/2017/03/Criminologia-GeneralI.pdf

Mendoza. H. (2008). La criminología como ciencia empírica. https://hectorberducido.files.wordpress.com/2008/05/n-criminologia-cienciaempirca.pdf

Nájera. G. X. (2014). Criminología, derecho penal y Puntos de encuentro epistemológico en la protección de los derechos humanos y la seguridad pública IUS. Revista del Instituto de Ciencias Jurídicas de Puebla A.C., vol. VIII, núm. 34, julio-diciembre, 2014, pp. 101-124 Instituto de Ciencias Jurídicas de Puebla A. C. Puebla, México. http://www.redalyc.org/articulo.oa?id=293233779007 